\title{
lodine Adsorption by Ag-Aerogel under Prototypical Vessel Off-Gas Conditions
}

\section{Fuel Cycle Technology}

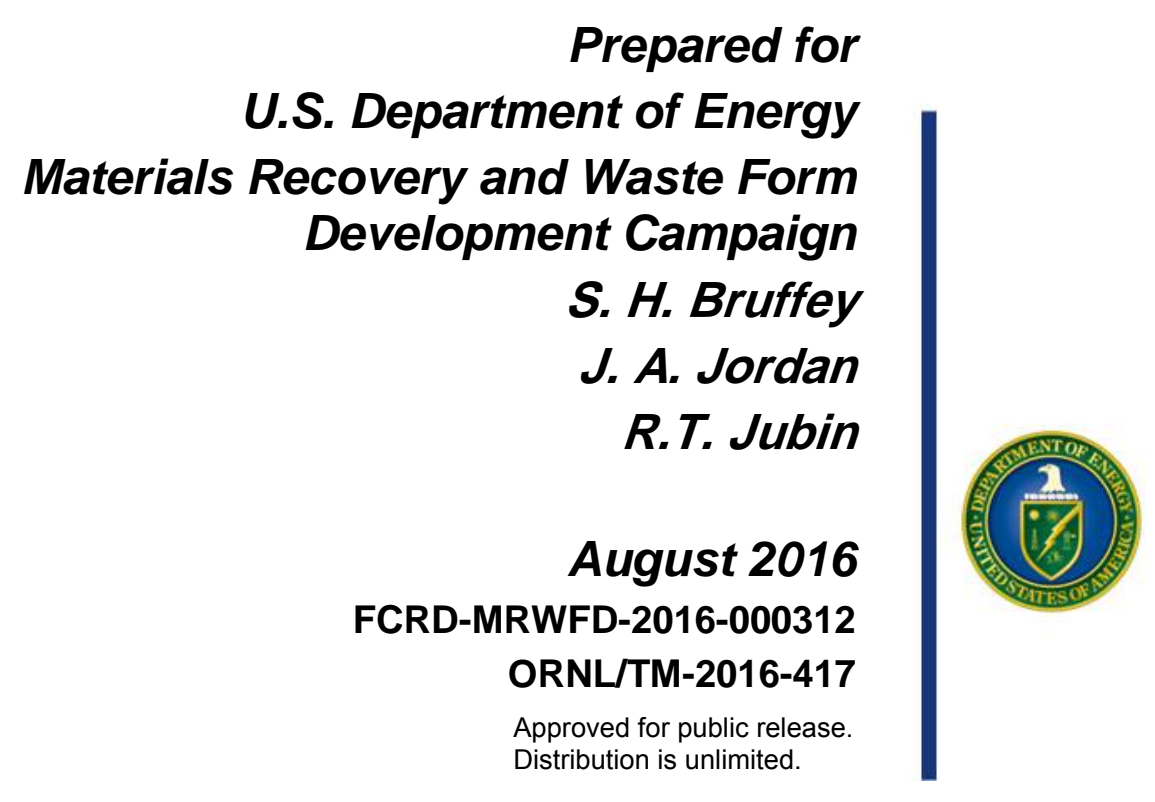





\section{DISCLAIMER}

This information was prepared as an account of work sponsored by an agency of the U.S. Government. Neither the U.S. Government nor any agency thereof, nor any of their employees, makes any warranty, expressed or implied, or assumes any legal liability or responsibility for the accuracy, completeness, or usefulness, of any information, apparatus, product, or process disclosed, or represents that its use would not infringe privately owned rights. References herein to any specific commercial product, process, or service by trade name, trade mark, manufacturer, or otherwise, does not necessarily constitute or imply its endorsement, recommendation, or favoring by the U.S. Government or any agency thereof. The views and opinions of authors expressed herein do not necessarily state or reflect those of the U.S. Government or any agency thereof. 



\section{SUMMARY}

U.S. regulations will require the removal of ${ }^{129}$ I from the off-gas streams of any used nuclear fuel (UNF) reprocessing plant prior to discharge of the off-gas to the environment. The required plant decontamination factor for iodine will vary based on fuel burnup, cooling time, and other factors but is very likely to be $>1000$ and could be as high as 8000 . Multiple off-gas streams within a UNF reprocessing plant combine prior to environmental release, and each of these streams contains some amount of iodine. To achieve the decontamination factors (DFs) that are likely to be required by regulations, iodine removal from the vessel off-gas will be necessary.

The vessel off-gas contains iodine at very dilute concentrations (ppb levels) and will also contain water vapor. Iodine species present are likely to include both elemental and organic iodides. There will also be solvent vapors and volatile radiolysis products. The United States has considered the use of silver-based sorbents for removal of iodine from UNF off-gas streams, but little is known about the behavior of those sorbents at very dilute iodine concentrations. The purpose of this study was to expose silverfunctionalized silica aerogel (AgAerogel) to a prototypical vessel off-gas stream containing $40 \mathrm{ppb}$ methyl iodide to obtain information about organic iodine capture by silver-sorbents at very low iodine concentrations. The design of this extended duration testing was such that information about the rate of adsorption, the penetration of the iodine species, and the overall system DF could be obtained.

Results show that $\mathrm{CH}_{3} \mathrm{I}$ penetrates into a AgAerogel sorbent bed to a depth of $3.9 \mathrm{~cm}$ under prototypical vessel off-gas conditions. An iodine loading of $22 \mathrm{mg} \mathrm{I} / \mathrm{g}$ AgAerogel was observed in the first $0.3 \mathrm{~cm}$ of the bed. Of the iodine delivered to the system, $48 \%$ could not be accounted for, and future efforts will investigate this concern. Direct calculation of the decontamination factor is not possible, as no iodine was observed to break through the sorbent beds.

Continued studies on the adsorption of iodine from prototypical vessel off-gas streams by silver-based sorbents will attempt to resolve some of the questions raised here, both regarding mass balance and the effect of aging on iodine adsorption by AgAerogel from a dilute gas stream. Additionally, the adsorption of different iodine species, such as $\mathrm{I}_{2}$ and $\mathrm{C}_{12} \mathrm{H}_{25} \mathrm{I}$ will be studied. Other variables that merit examination are the gas velocity of the test and the dependence of the observed results on the inlet iodine concentration. Finally, longer duration testing should be considered in an effort to determine the mass transfer zone associated with iodine adsorption by AgAerogel under prototypical vessel off-gas conditions. The estimation of mass transfer zone is required for any future industrial implementation. 
This page intentionally left blank. 


\section{CONTENTS}

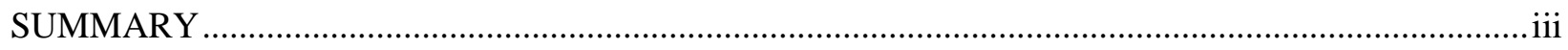

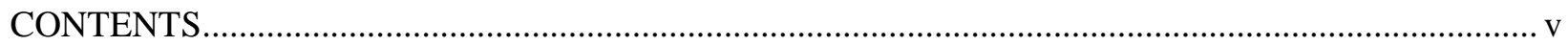

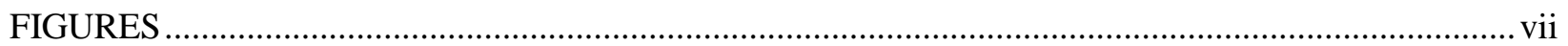

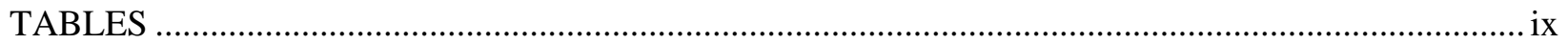

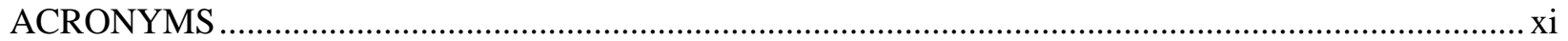

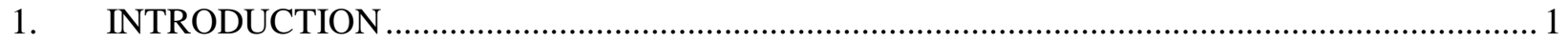

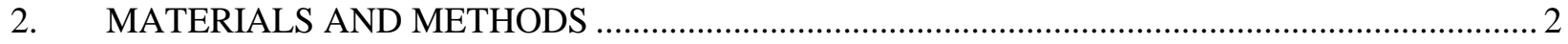

$2.1 \quad$ Experimental Materials ................................................................................................. 2

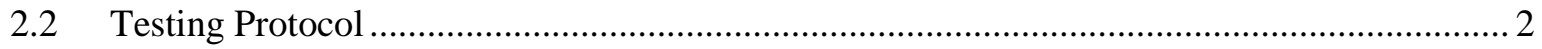

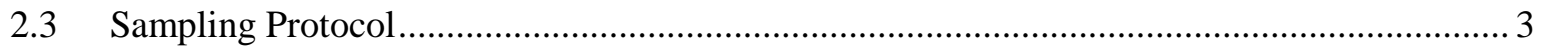

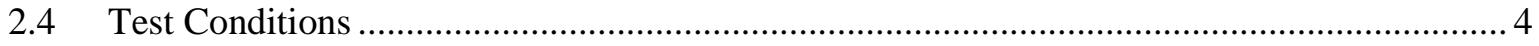

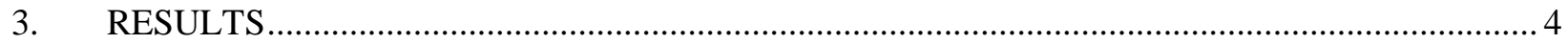

3.1 Adsorption onto a Thin Bed....................................................................................... 4

3.2 Penetration of $\mathrm{CH}_{3} \mathrm{I}$ into the Sorbent Bed....................................................................... 5

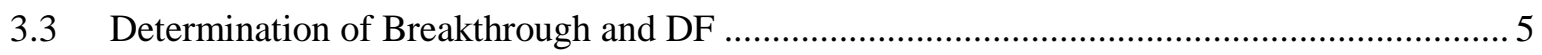

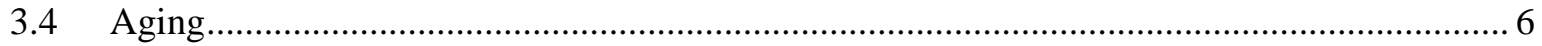

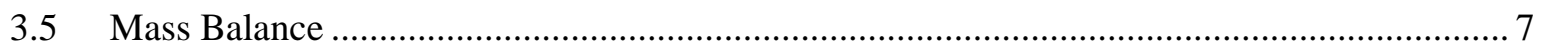

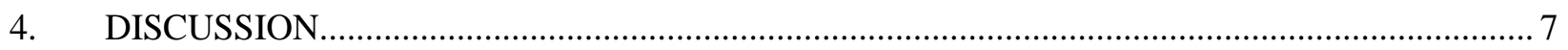

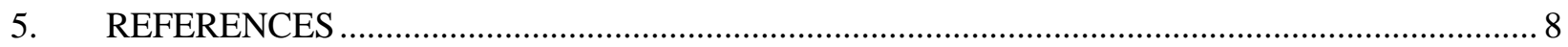


This page intentionally left blank. 


\section{FIGURES}

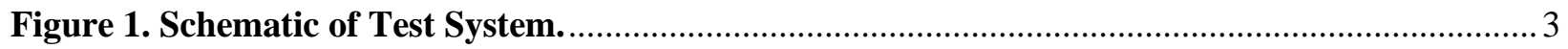

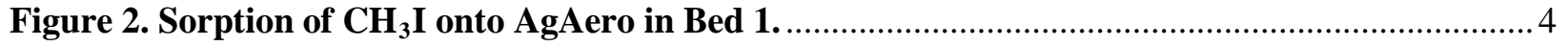

Figure 3. Penetration of $\mathbf{C H}_{3} \mathrm{I}$ into an AgAero Sorbent Bed. ......................................................... 5

Figure 4. Aging Effects Observed in the Adsorption of $\mathbf{C H}_{3} \mathrm{I}$ onto AgAero.................................... 7 
This page left intentionally blank. 
Iodine Adsorption by Ag-Aerogel under Prototypical Vessel Off-Gas Conditions

August 31, 2016

\section{TABLES}

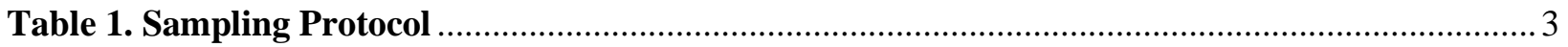


This page intentionally left blank. 


\section{ACRONYMS}

$\begin{array}{ll}\text { AgAerogel } & \text { silver-functionalized silica-aerogel } \\ \text { AgZ } & \text { silver-exchanged mordenite } \\ \text { COG } & \text { cell off-gas } \\ \text { DF } & \text { decontamination factor } \\ \text { HFIR } & \text { High Flux Isotope Reactor } \\ \text { DOG } & \text { dissolver off-gas } \\ \text { NAA } & \text { neutron activation analysis } \\ \text { ORNL } & \text { Oak Ridge National Laboratory } \\ \text { SOG } & \text { shear off-gas } \\ \text { UNF } & \text { used nuclear fuel } \\ \text { VOG } & \text { vessel off-gas } \\ \text { WOG } & \text { waste off-gas }\end{array}$


This page intentionally left blank. 


\section{IODINE ADSORPTION BY Ag-AEROGEL UNDER PROTOTYPICAL VESSEL OFF-GAS CONDITIONS}

\section{INTRODUCTION}

U.S. regulations will require the removal of ${ }^{129}$ I from the off-gas streams of any used nuclear fuel (UNF) reprocessing plant prior to discharge of the off-gas to the environment. The release of volatile radioactive iodine is governed by three regulations in the United States (40 CFR 61, 40 CFR 190, and 10 CFR 20). These regulations govern both total release limits for iodine and the potential combined dose from the four volatile radionuclides of most concern for reprocessing $\left({ }^{3} \mathrm{H},{ }^{14} \mathrm{C},{ }^{85} \mathrm{Kr}\right.$, and $\left.{ }^{129} \mathrm{I}\right)$. The required plant decontamination factor (DF) for iodine will vary based on fuel burnup, cooling time, and other factors but is very likely to be $>1000$ and could be as high as 8000 (Jubin 2012).

Multiple off-gas streams within a UNF reprocessing plant combine prior to environmental release, and each of these streams contains some amount of iodine. For an aqueous UNF reprocessing plant, these streams include the dissolver off-gas (DOG), the cell off-gas (COG), the vessel off-gas (VOG), the waste off-gas (WOG) and the shear off-gas (SOG). As 95-98\% of the total iodine inventory of UNF is released to the DOG, complete removal of iodine from the DOG without treatment of other streams would result in a plant DF of $<100$ (Jubin 2013). Thus, to achieve regulatory compliance, treatment of multiple off-gas streams within the plant must be performed.

This conclusion motivates the investigation of iodine removal from the VOG. Vessel off-gas refers to the gas venting all chemical process tanks and equipment in the primary (non-waste) process line downstream of dissolver operations, including the solvent extraction operations that occur during aqueous UNF reprocessing. Any volatile components present in the solvent extraction vessels can transfer to this gas. The VOG will most likely contain iodine at ppb concentrations. It is possible that organic solvents will be present, along with some of their radiolytic degradation products. The VOG is also the stream most likely to contain organic iodides, which are commonly considered more difficult to remove with traditional sorbents than elemental iodine ( $\left.\mathrm{I}_{2}\right)$ (Bruffey 2015b).

Studies have been completed on the adsorption of iodides (both elemental and organic) onto silver mordenite (AgZ) from prototypical VOG streams (Jubin et al. 2015; Bruffey et al. 2016). AgZ has long been considered for use as an iodine sorbent in UNF reprocessing plants, but recent efforts have identified silver-functionalized silica-aerogel (AgAerogel) as a potential alternative iodine sorbent. AgAerogel demonstrates a resistance to degradation from $\mathrm{NO}_{\mathrm{x}}$ gases present within the plant, has high iodine loadings by weight, and is easily converted to a condensed waste form through hot isostatic pressing (Bruffey et al. 2015a; Matyas et al. 2016). However, the mechanism for iodine adsorption and immobilization by AgAerogel is not yet understood, and it is not currently available in an engineered form that would have a large particle size and that would be resistant to mechanical degradation. Additionally, low-concentration iodine adsorption behaviors have not yet been investigated for these materials. In an effort to better understand how AgAerogel would perform in a UNF plant where high DFs are required across varied stream compositions, the adsorption of $\mathrm{CH}_{3} \mathrm{I}$ onto AgAerogel was characterized through extended duration testing under prototypic VOG conditions. 


\section{MATERIALS AND METHODS}

\subsection{Experimental Materials}

AgAerogel was obtained from Pacific Northwest National Laboratory, where it is produced in 100-g scale batches. This material was determined by Oak Ridge National Laboratory (ORNL) to have a bulk density of $0.62 \mathrm{~g} / \mathrm{mL}$. No information on fundamental material properties, such as silver content or particle size, was provided with the AgAerogel.

Because iodine can be corrosive, especially in the presence of water, the materials of construction for the system were carefully selected to minimize iodine retention by system components and piping. The sorbent beds were contained within glass columns (internal diameter $=3.45 \mathrm{~cm}$ ) and separated by glass frits. The humid air and $\mathrm{CH}_{3} \mathrm{I}$ streams were piped through separate lines of 316 stainless steel tubing. The two streams were blended together directly prior to introduction into the sorbent bed through the use of a glass tee.

\subsection{Testing Protocol}

The test system was designed with three sorbent beds placed in series. The first bed (Bed 1) was a thin bed with an approximate sorbent depth of $0.2 \mathrm{~cm}$. This test bed was segmented into quadrants. The quadrants and test system are shown in Figure 1. Bed 1 was intended to measure the adsorption rate of iodine onto the sorbent during the test period by removing and replacing sorbent material from the quadrants at selected time intervals. The second sorbent bed (Bed 2) was approximately $11 \mathrm{~cm}$ deep, and the sorbent remained online for the duration of testing. Bed 2 was intended to measure the depth of the mass transfer zone for the conditions used during testing. The third bed (Bed 3) was $0.5 \mathrm{~cm}$ deep and was periodically removed and replaced throughout the test. Bed 3 was intended to detect breakthrough. The online time for each sorbent bed or quadrant is shown in Table 1. 


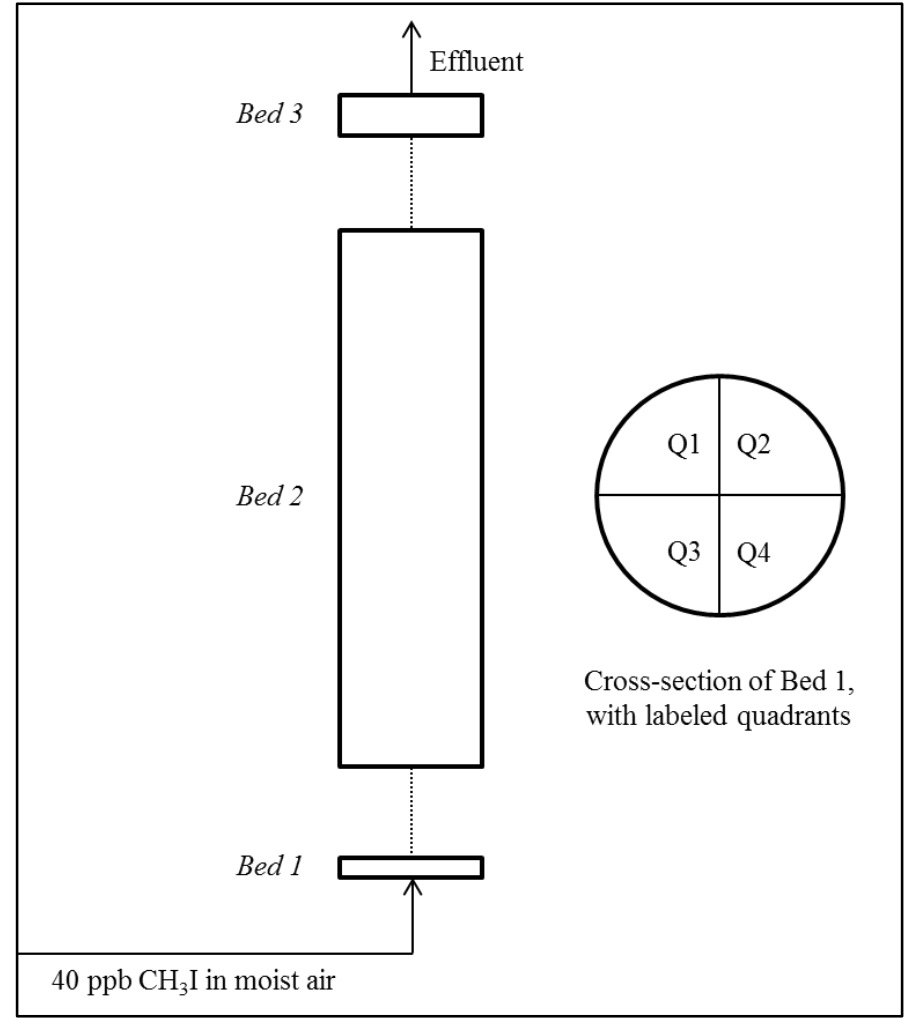

Figure 1. Schematic of Test System.

Table 1. Sampling Protocol

\begin{tabular}{llllll}
\hline \multicolumn{2}{l}{ Cumulative Time Online } & & & \\
\hline \multicolumn{2}{l}{ Bed 1 (adsorption rate) } & \multicolumn{2}{l}{ Bed 2 (mass transfer zone) } & Bed 3 (breakthrough) \\
\hline Sample & $\begin{array}{l}\text { Time } \\
\text { online } \\
\text { (weeks) }\end{array}$ & Sample & $\begin{array}{l}\text { Time online } \\
\text { (weeks) }\end{array}$ & Sample & $\begin{array}{l}\text { Time online } \\
\text { (weeks) }\end{array}$ \\
\hline Q1-1 & 1 & All & 16 & $3 \mathrm{~A}$ & 4 \\
Q2-1 & 4 & & $3 B$ & 4 \\
Q3-1 & 8 & & $3 \mathrm{C}$ & 4 \\
Q4-1 & 16 & & $3 \mathrm{D}$ & 2.1 \\
Q1-2* & 15 & & $3 \mathrm{E}$ & 1.9 \\
Q2-2* & 12 & & & \\
Q3-2* & 8 & & &
\end{tabular}

\subsection{Sampling Protocol}

Sampling events consisted of removal of the sorbent within the selected quadrant or sample bed followed by replacement with fresh sorbent. Upon completion of the test, Bed 2 was removed in discrete sections to allow the progress of the sorbent front through the bed to be determined. All samples were analyzed by neutron activation analysis (NAA) at ORNL's High Flux Isotope Reactor (HFIR) to determine iodine content. 


\subsection{Test Conditions}

This test studied the adsorption of methyl iodide $\left(\mathrm{CH}_{3} \mathrm{I}\right)$ onto AgAerogel. The feed stream consisted of iodine in a moist air stream with a dew point of $0^{\circ} \mathrm{C}$. The concentration of $\mathrm{CH}_{3} \mathrm{I}$ was $40 \mathrm{ppb}$ and was supplied from a compressed-gas cylinder containing a $\mathrm{CH}_{3} \mathrm{I} / \mathrm{N}_{2}$ blend gas. The sorbent beds were held at $150^{\circ} \mathrm{C}$, and the gas stream was preheated to $150^{\circ} \mathrm{C}$ prior to contact with the sorbent beds. A superficial gas velocity of $10 \mathrm{~m} / \mathrm{min}$ was calculated by using the empty column diameter of $3.45 \mathrm{~cm}$.

\section{RESULTS}

\subsection{Adsorption onto a Thin Bed}

The quadrants of Bed 1were sampled according to Table 1. The iodine loading as a function of time was obtained from the quadrants and is shown in Figure 2. Sample Q3-1 is pending analysis. The error bars of the neutron activation analysis are smaller than the data points, but some error may result from analyzing only a portion of the homogenized sample if the homogenization is not fully complete. A more quantifiable estimate of this error is ongoing. As expected, total adsorbed iodine increases with respect to time over the 16 week test to an iodine loading of $22 \mathrm{mg} \mathrm{I} / \mathrm{g}$ AgAerogel.

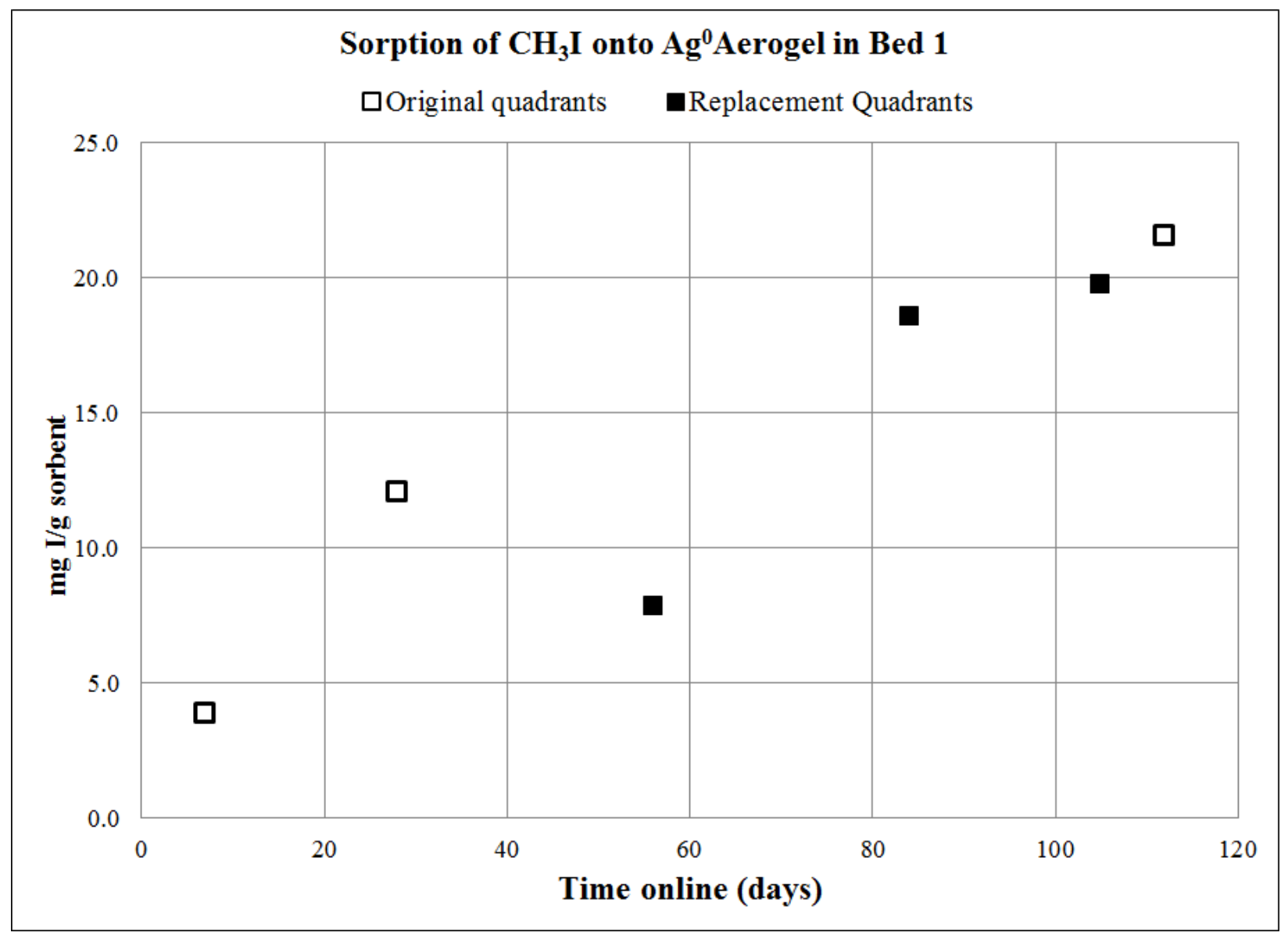

Figure 2. Sorption of $\mathrm{CH}_{3} \mathrm{I}$ onto AgAerogel in Bed 1. 


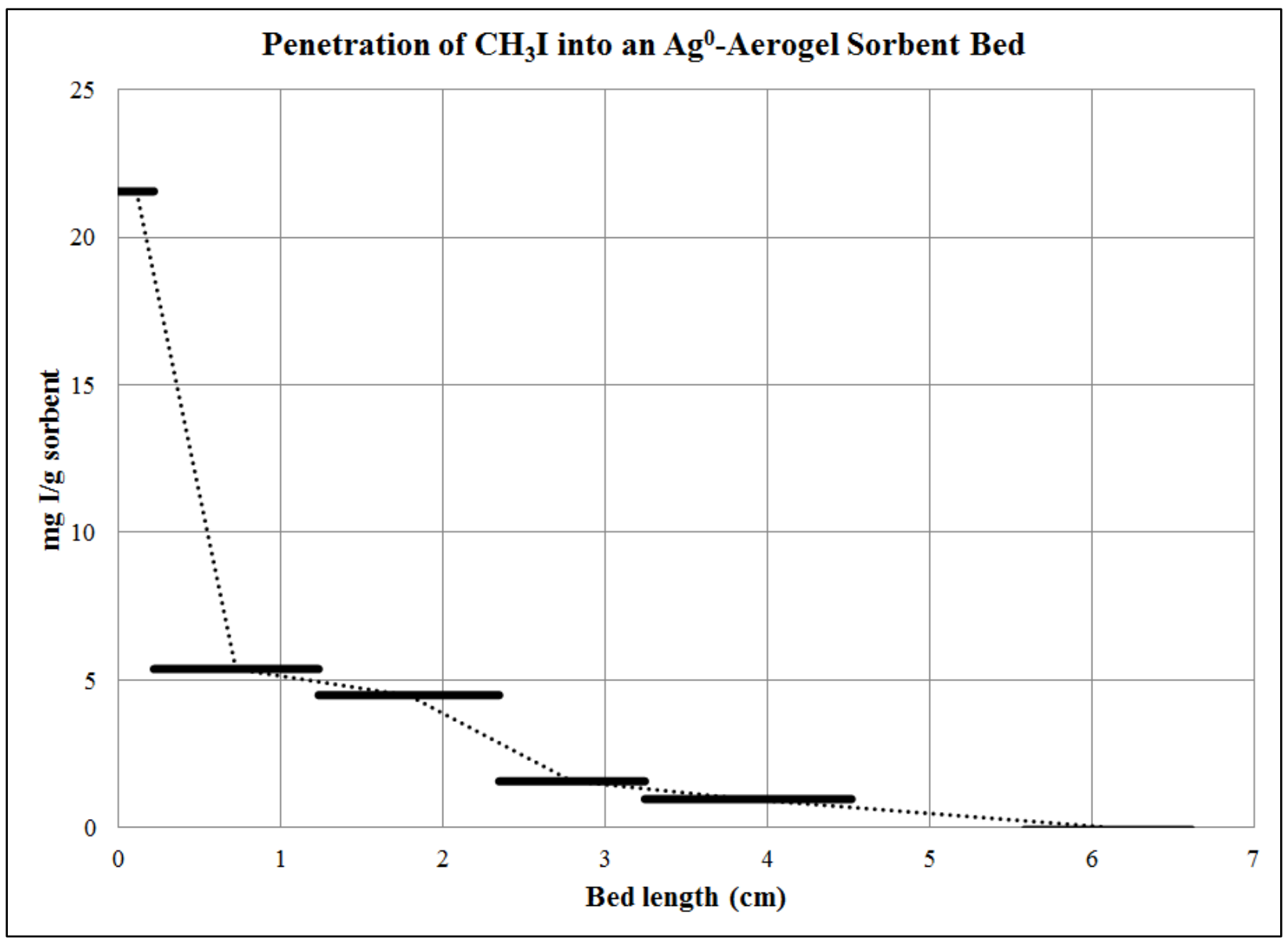

Figure 3. Penetration of $\mathrm{CH}_{3} \mathrm{I}$ into an AgAerogel Sorbent Bed.

\subsection{Penetration of $\mathrm{CH}_{3} \mathrm{I}$ into the Sorbent Bed}

Bed 2 was removed in sections by vacuum. The sections were each homogenized, and then a small portion was removed for analysis and considered to be the average loading for that section. As shown in Figure 3, $\mathrm{CH}_{3} \mathrm{I}$ was observed to penetrate $3.9 \mathrm{~cm}$ into the sorbent bed. For purposes of this testing, the maximum extent of penetration is defined as the midpoint of the first section containing $<1 \mathrm{mg} \mathrm{I} / \mathrm{g}$ sorbent. The black bars represent the length of sorbent bed that was removed and homogenized prior to analysis and the average loading of that section. The dotted line is plotted through the midpoint of the section length. Analysis results from the fifth Bed 2 segment are pending.

The section length was based upon the density of the as-received material and the weight of each removed section. The density of the material may be altered during testing as the material contacts a humid air stream. Fines were also observed upon test conclusion.

\subsection{Determination of Breakthrough and DF}

Periodic removal and replacement of Bed 3 as detailed in Table 1 was intended to detect breakthrough of Bed 2 and allow the subsequent calculation of the DF. There is one key assumption in this approach - that the sorbent in Bed 3 is effective at concentrations well below the feed concentration, thus adsorbing all iodine contacting it. 
Equation 1 is used to calculate the concentration in the gas stream exiting Bed 2. Some extent of breakthrough must be detected to avoid division by zero in the calculation of the DF by Equation 2 .

(Equation 1)

$$
\left[\mathrm{CH}_{3} I\right]_{\text {Bed } 2 \text { outlet }}=\frac{g \text { I recovered per Bed } 3 \text { sample }}{\text { Gas flow rate } \times \text { sample time online }}
$$

(Equation 2)

$$
\text { Decontamination Factor }=\frac{\left[\mathrm{CH}_{3} I\right]_{\text {in }}}{\left[\mathrm{CH}_{3} I\right]_{\text {out }}}
$$

However, in this experiment no iodine was observed in Bed 3 above the detection limit for the NAA. The level of detection for NAA is $0.045 \mathrm{mg} \mathrm{I} / \mathrm{g}$ sorbent. An estimate of the DF for the system can be made by making a number of assumptions. First, it is assumed that all of the $\mathrm{CH}_{3} \mathrm{I}$ passing through Bed 2 is subsequently trapped on Bed 3 and that the Bed 3 iodine loading corresponds to the amount of iodine that would be present at the level of the detection limit. Then by using the Bed 3 sample size of $3 \mathrm{~g}$ with an online time of four weeks, the concentration of the $\mathrm{CH}_{3} \mathrm{I}$ exiting Bed 2 is calculated to be 105 parts-pertrillion (ppt). Based on the intended feed concentrations of $40 \mathrm{ppb}$ the resulting DF based on Eqn. 2 is 382. This value is thought to be below the actual DF, is an artifact of the approach used and is limited by 1) the detection limit for NAA and 2) the time the sample was on line. If the time on line had been greater for the Bed 3 samples, the calculated exit concentration would be reduced per Eqn. 1. In a like manner, the calculated exit concentration would also be reduced if the detection limit was lower.

While the samples in Bed 3 were periodically replaced, all of Bed 2 was on line for the entire run duration of 16 weeks. The loading on Bed 1 and on the first several centimeters of Bed 2 represents the leading edge of the mass transfer zone. If the final portion of Bed 2 with a mass of $7 \mathrm{~g}$ is considered as a sampler for the amount of $\mathrm{CH}_{3} \mathrm{I}$ leaving the mass transfer zone of the bed, then applying Eqn. 1 yields a value of $61 \mathrm{ppt}$ in the effluent using the assumptions previously detailed, and the resultant DF is 652.

To demonstrate a DF of 1000 for this system, i.e., to determine a $\mathrm{CH}_{3} \mathrm{I}$ gas concentration of $40 \mathrm{ppt}$ in the gas phase using a $3 \mathrm{~g}$ Bed 3 on-line for four weeks, would require a NAA detection limit of $0.0 .017 \mathrm{mg}$ $\mathrm{I} / \mathrm{g}$ sorbent. This is roughly 3 times lower than the current detection limit of $0.045 \mathrm{mg} \mathrm{I} / \mathrm{g}$ sorbent. However, by increasing the online time of the sampler bed to 16 weeks, the required detection limit would be $0.070 \mathrm{mg} \mathrm{I} / \mathrm{g}$ sorbent and above the current detection limit. Alternatively, holding the sampler time online constant and decreasing the sample size to $1 \mathrm{~g}$ would then require a detection limit of 0.052 $\mathrm{mg} \mathrm{I/g}$ sorbent, again above the current detection limit.

\subsection{Aging}

The removal of Bed 1 quadrants over the course of the study provided iodine-loaded sorbent material that was online for varying time periods. This allowed the potential effect of sorbent aging to be explored. In Figure 4, the average iodine loading rate is plotted as a function of the time the sorbent bed was online. A decrease in $\mathrm{CH}_{3} \mathrm{I}$ adsorption rate was observed for this study for the original quadrants, but this was not duplicated by the replacement quadrants. 


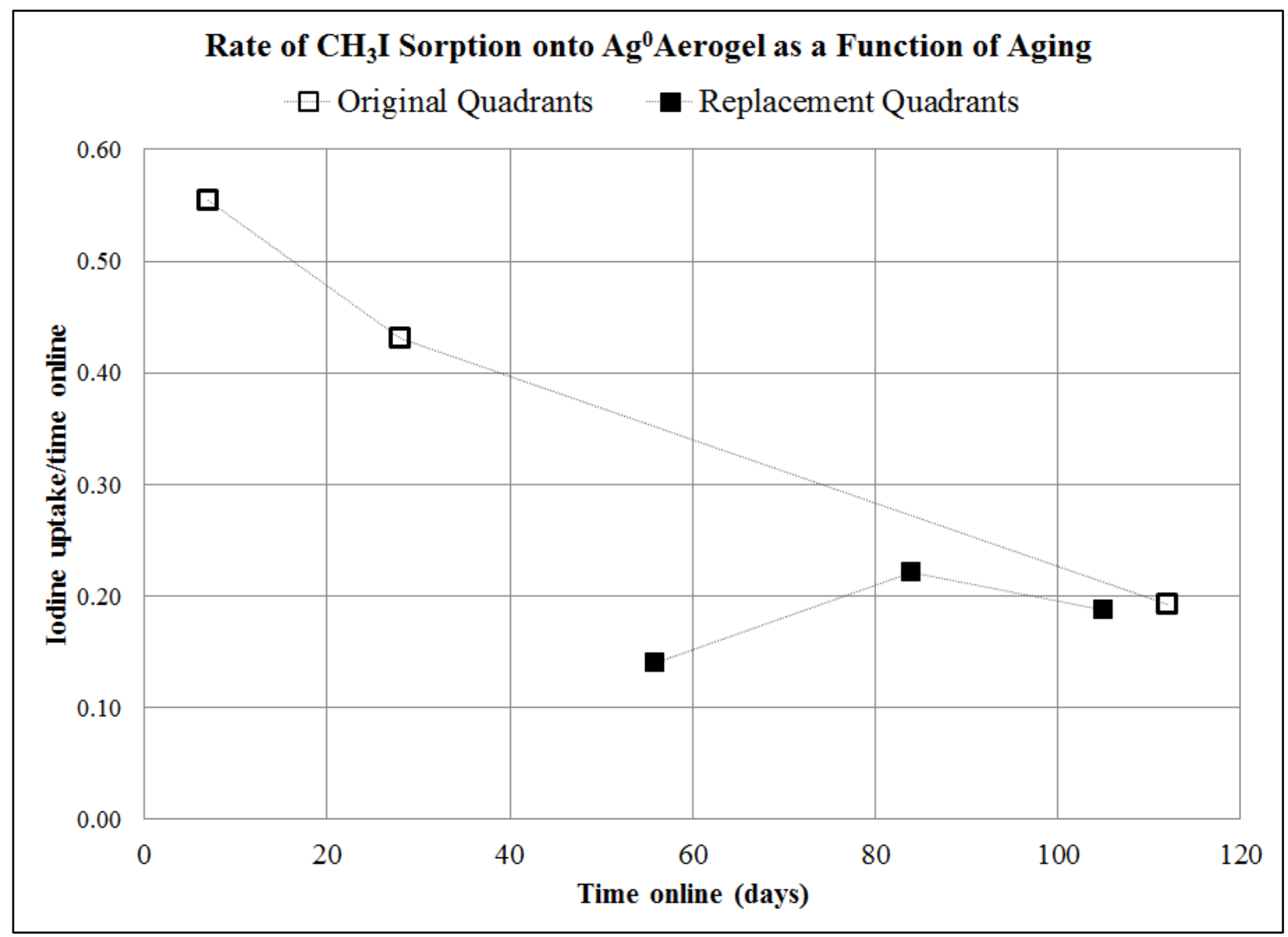

Figure 4. Aging Effects Observed in the Adsorption of $\mathrm{CH}_{3} \mathrm{I}$ onto AgAerogel.

\subsection{Mass Balance}

As a check of the system, the total amount of iodine recovered from the sorbent bed was compared to the intended delivery amount. It was found that while $0.21 \mathrm{~g}$ I was delivered, only $0.11 \mathrm{~g}$ I was recovered on the sorbent beds, leaving $48 \%$ of the iodine delivered unaccounted for. The origin of this discrepancy is yet to be determined.

\section{DISCUSSION}

The penetration of $\mathrm{CH}_{3} \mathrm{I}$ into the AgAerogel bed was observed to be $3.9 \mathrm{~cm}$. Direct calculation of the DF is not possible as no measurable iodine break through of the sorbent beds was observed. Compliance with regulations is likely to require a DF of $\sim 1000$ for the VOG. An exercise in DF estimation indicates that future testing could be conducted in such a way as to demonstrate a DF of 1000 using current analytical detection limits, assuming breakthrough of Bed 2 occurs. The success of such a demonstration would be dependent on iodine breaking through the sorbent beds and successful recovery of that iodine from the gas stream at concentrations below 40 ppt. 
August 31, 2016

While a decrease in iodine uptake as a function of time online was observed for the original four quadrants, this is not conclusive proof of an aging effect. The replacement quadrants do not replicate the trend of the original quadrants, with only the replacement quadrant longest online having comparable loading to that of the original quadrants. To eliminate sample homogenization as a concern, additional NAA analysis will be performed on duplicate samples from each quadrant.

There are outstanding questions concerning the aging of the sorbent bed in any off-gas system, but especially in a vessel off-gas system. Aging of a sorbent for extended periods of time in a flowing gas stream is known to result in a decrease in iodine capacity (Bruffey 2015a). However, the capacity of the aged sorbent is measured through exposure to prototypical DOG streams containing ppm levels of iodine; the iodine capacity of aged material in very dilute iodine-containing streams has not been studied. Additionally, aging studies have been limited to the adsorption of elemental iodine $\left(\mathrm{I}_{2}\right)$; extension of this work to evaluate impacts of aging on $\mathrm{CH}_{3} \mathrm{I}$ adsorption has not been performed. Finally, it is difficult to elucidate whether a decrease in iodine uptake over time reflects an approach to the unknown saturation level of the aged sorbent or whether aging also effects the kinetics of iodine adsorption. Future experiments should examine methods to resolve these knowledge gaps.

The mass balance for iodine within the system was unable to be closed, with $48 \%$ of iodine delivered not found on the sorbent beds. The following are offered as potential causes. First, the amount of iodine successfully delivered to the system could have been less than expected due to $\mathrm{CH}_{3} \mathrm{I}$ holdup within the feed system, mass flow meter error, or other feed system problems. Second, the samples are removed from the system by vacuum. Although chemisorbed iodine will not be affected by this process, any iodine that is only physisorbed could have been lost during this vacuum operation. Finally, it is possible that AgAerogel is unable to adsorb iodine from a dilute gas stream below some limiting concentration, which would result in iodine passing through the bed undetected by the methods used for this study. It is important to note that if less iodine was delivered to the bed than was intended, or if iodine passed through the bed undetected, the resultant DF could be smaller than estimated here.

Future efforts on the adsorption of iodine from prototypical vessel off-gas streams by silver-based sorbents will attempt to resolve some of the questions raised here, both regarding mass balance and the effect of aging on iodine adsorption by AgAerogel from a dilute gas stream. Additionally, the adsorption of different iodine species, such as $\mathrm{I}_{2}$ and $\mathrm{C}_{12} \mathrm{H}_{25} \mathrm{I}$, will be studied. Other variables that merit examination are the gas velocity of the test and the dependence of the observed results on the inlet iodine concentration. Finally, longer duration testing should be considered in an effort to determine the mass transfer zone associated with iodine adsorption by AgAerogel under prototypical vessel off-gas conditions. The estimation of mass transfer zone is required for any future industrial implementation.

\section{REFERENCES}

Bruffey, S. H., K. K. Patton, R. T. Jubin. 2015a. Complete Iodine Loading of NO Aged Ag0functionalized Aerogel. ORNL/LTR-2015/258. UT-Battelle, LLC, Oak Ridge National Laboratory, May 2015.

Bruffey, S. H., R. T. Jubin, D. M. Strachan, B. B. Spencer, B. J. Riley. 2015b. Literature Survey to Identify Potentially Problematic Volatile Iodine-bearing Species Present in Off-gas Streams. ORNL/SPR-2015/290. UT-Battelle, LLC, Oak Ridge National Laboratory, June 2015.

Bruffey, S. H., R. T. Jubin, J. A. Jordan. 2016. "Capture of Elemental and Organic Iodine from Dilute Gas Streams by Silver-exchanged Mordenite.” Procedia Chemistry, in press.

Jubin, R. T., N. R. Soelberg, D. M. Strachan, and G. Ilas. Fuel Age Impacts on Gaseous Fission Product Capture During Separations. Report No. FCRD-SWF-2012-000089, UT-Battelle, LLC, Oak Ridge National Laboratory, 2016. 
Jubin, R. T., D. M. Strachan, and N. R. Soelberg, and G. Ilas. Iodine Pathways and Off-Gas Stream Characteristics for Aqueous Reprocessing Plants-A Literature Survey and Assessment. Report No. FCRD-SWF-2013-000308, UT-Battelle, LLC, Oak Ridge National Laboratory, 2013.

Jubin, R. T., S. H., Bruffey, and B. B. Spencer. "Performance of Silver-exchanged Mordenite for Iodine Capture under Vessel Off-gas Conditions.” Proceedings of Global 2015, September 2015.

Matyas, J., N. Canfield, S. Sulaiman, M. Zumhoff. "Silica-based Waste Form for Immobilization of Iodine from Reprocessing Off-gas Streams.” J. Nucl. Materials, vol. 476, 255-261. August 2016. 